\title{
Double-Stranded Helix of Xanthan in Dilute Solution: Further Evidence
}

\author{
Takahiro SATo, Sakiko KoJIMA, Takashi NORISUYE, \\ and Hiroshi FujITA \\ Department of Macromolecular Science, Osaka University, \\ Toyonaka, Osaka 560, Japan
}

(Received March 6, 1984)

\begin{abstract}
Viscosity measurements were made on ten samples of a bacterial polysaccharide xanthan in $0.1 \mathrm{M}$ aqueous $\mathrm{NaCl}$ and cadoxen (at $25^{\circ} \mathrm{C}$ ); the polymer dissolves as dimers in the former and as monomers in the latter. Intrinsic viscosities [ $\eta]$ as a function of molecular weight in $0.1 \mathrm{M}$ aqueous $\mathrm{NaCl}$ fitted to Yamakawa-Yoshizaki's theory for the Kratky-Porod wormlike chain with a linear mass density $M_{\mathrm{L}}$ of $1940 \mathrm{~nm}^{-1}$, a persistence length of $120 \mathrm{~nm}$, and a chain diameter of $2.0-2.5 \mathrm{~nm}$. This $M_{\mathrm{L}}$ corresponds to the $0.47 \mathrm{~nm}$ pitch (per main chain glucose residue) of the $5_{1}$ double-stranded helix proposed for the crystalline structure of xanthan, and is consistent with the previous conclusion from light scattering that the xanthan dimer in $0.1 \mathrm{M}$ aqueous $\mathrm{NaCl}$ has this helical structure. On the other hand, the values of $[\eta]$ in cadoxen showed that the single chain of xanthan in this solvent is essentially flexible. Those in mixtures of cadoxen and water decreased sharply with an increase in cadoxen composition in a range from 60 to $70 \mathrm{wt} \%$ cadoxen. The double-helical xanthan dimer was not restored once dissociated into single chains in pure cadoxen at $25^{\circ} \mathrm{C}$ or in pure water at $95^{\circ} \mathrm{C}$.
\end{abstract}

KEY WORDS Xanthan / Polysaccharide / $\beta$-1,4-D-Glucan / Double Helix /

Persistence Length / Semiflexible Chain / Intrinsic Viscosity /

In a previous study, ${ }^{1}$ we found from light scattering measurements that xanthan, an extracellular, ionic polysaccharide produced by the bacterium Xanthomonas campestris, dissolves in $0.1 \mathrm{M}$ aqueous sodium chloride $(\mathrm{NaCl})$ as rodlike double-helical dimers. This finding was based on the following experimental observations: (1) The weight-average molecular weights $M_{w}$ of $\mathrm{Na}$ salt xanthan samples in $0.1 \mathrm{M}$ aqueous $\mathrm{NaCl}$ were about twice as large as those in cadoxen in which $\mathrm{Na}$ salt xanthan disperses as single chains. (2) For $M_{w}$

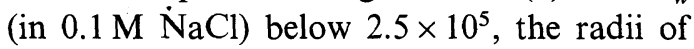
gyration $\left\langle S^{2}\right\rangle^{1 / 2}$ in $0.1 \mathrm{M}$ aqueous $\mathrm{NaCl}$ were proportional to $M_{w}$. (3) The contour length per main chain glucose residue estimated from $\left\langle S^{2}\right\rangle^{1 / 2}$ agreed with the pitch (per glucose residue) of the $5_{1}$ double-stranded helix proposed by Okuyama et al. ${ }^{2}$ for the crystalline structure of xanthan.

Recently, we extended measurement to the viscosity of $\mathrm{Na}$ salt xanthan in $0.1 \mathrm{M}$ aqueous $\mathrm{NaCl}$, cadoxen, and mixtures of cadoxen and water. This paper presents the experimental data obtained, along with a comment on the spectroscopic studies of xanthan by previous investigators. $^{3-5}$

\section{EXPERIMENTAL}

\section{Samples}

To the previous six xanthan samples ${ }^{1}(\mathrm{X} 4-5$, X3-5, X7-3b, X6-4-4, X8-3-5, and X8-3-8) were added four samples, designated below as X5-6, X9-3, X6-3-7, and X10-4. The new samples were prepared from a commercial sample (Kelco Keltrol) by sonication followed by fractionation. All the ten samples were 
converted to the $\mathrm{Na}$ salt form, and their $0.1 \mathrm{M}$ aqueous $\mathrm{NaCl}$ and cadoxen solution were prepared by the methods ${ }^{1}$ described previously.

The weight-average molecular weights of the four Na salt samples X5-6, X9-3, X6-3-7, and $\mathrm{X} 10-4$ in $0.1 \mathrm{M}$ aqueous $\mathrm{NaCl}$ and cadoxen at $25^{\circ} \mathrm{C}$ were determined by light scattering (see ref 1 for the details of experimental procedures).

\section{Viscometry}

Zero shear-rate viscosities of $\mathrm{Na}$ salt xanthan in $0.1 \mathrm{M}$ aqueous $\mathrm{NaCl}$ and cadoxen at $25^{\circ} \mathrm{C}$ were determined by low-shear four-bulb capillary viscometers for samples X4-5, X5-6, $\mathrm{X} 3-5, \mathrm{X} 9-3, \mathrm{X} 7-3 \mathrm{~b}$, and X6-3-7 in $0.1 \mathrm{M}$ aqueous $\mathrm{NaCl}$ and samples $\mathrm{X} 4-5$ and $\mathrm{X} 5-6$ in cadoxen) or conventional capillary viscometers of the Ubbelohde type (for others). Huggins' and Mead-Fuoss' plots ${ }^{6,7}$ were used to estimate the intrinsic viscosity $[\eta]$ and the Huggins constant $k^{\prime}$.

Although no time dependence of scattering intensity was observed for cadoxen solutions in the previous and present light scattering measurements, flow times of these solutions decreased gradually and steadily with time. This decrease suggests a gradual shear-induced degradation of $\mathrm{Na}$ salt xanthan in cadoxen. Similar degradation was observed for cellulose in cadoxen* by Henley. ${ }^{8}$ The values of $[\eta]$ for samples $X 9-3$ and X7-3b in cadoxen determined immediately and $24 \mathrm{~h}$ after the preparation of the solutions showed no difference more than $2 \%$. For this reason, all the viscosity data in cadoxen reported below were taken within $10 \mathrm{~h}$ after the preparation of the solutions.

The composition dependence of $[\eta]$ in mixtures of cadoxen and water at $25^{\circ} \mathrm{C}$ was determined for three samples $\mathrm{X} 9-3, \mathrm{X} 7-3 \mathrm{~b}$, and $\mathrm{X} 10-4$. Correction for shear-rate effect was made except for sample X7-3b. Test solutions were prepared by dissolving a given sample directly into water-cadoxen mixtures of desired composition, and their viscosities were measured within $10 \mathrm{~h}$ after this operation. Densities of these mixtures were determined at $25^{\circ} \mathrm{C}$.

\section{RESULTS AND DISCUSSION}

Intrinsic Viscosity-Molecular Weight Relations

Table I summarizes the values of $M_{w},[\eta]$, and $k^{\prime}$ for all the $\mathrm{Na}$ salt xanthan samples in $0.1 \mathrm{M}$ aqueous $\mathrm{NaCl}$ and cadoxen at $25^{\circ} \mathrm{C}$,

Table I. Values of $M_{w}$, [ $\eta$, and $k^{\prime}$ for $\mathrm{Na}$ salt xanthan samples in $0.1 \mathrm{M}$ aqueous $\mathrm{NaCl}$ and cadoxen at $25^{\circ} \mathrm{C}$

\begin{tabular}{|c|c|c|c|c|c|c|c|}
\hline \multirow{2}{*}{ Sample } & \multicolumn{3}{|c|}{$0.1 \mathrm{M} \mathrm{NaCl}$} & \multicolumn{3}{|c|}{ Cadoxen } & \multirow{2}{*}{$\frac{M_{w}(\text { in } 0.1 \mathrm{M} \mathrm{NaCl})}{M_{w}(\text { in cadoxen })}$} \\
\hline & $10^{-4} M_{w}$ & $10^{-2}[\eta] / \mathrm{cm}^{3} \mathrm{~g}^{-1}$ & $k^{\prime}$ & $10^{-4} M_{w}$ & $10^{-2}[\eta] / \mathrm{cm}^{3} \mathrm{~g}^{-1}$ & $k^{\prime}$ & \\
\hline$X 4-5$ & 740 & 90.0 & 0.46 & 356 & 8.70 & 0.34 & $2.08^{\mathrm{a}}$ \\
\hline X5-6 & 394 & 51.1 & 0.42 & 196 & 6.45 & 0.34 & 2.01 \\
\hline X3-5 & 142 & 18.0 & 0.42 & 74.3 & 3.10 & 0.37 & $1.91^{\mathrm{a}}$ \\
\hline X9-3 & 99.4 & 10.1 & 0.37 & 49.3 & 2.24 & 0.37 & 2.02 \\
\hline$\times 7-3 b$ & 60.3 & 5.75 & 0.40 & 29.5 & 1.53 & 0.35 & $2.04^{\mathrm{a}}$ \\
\hline X6-3-7 & 36.2 & 3.20 & 0.39 & 17.7 & 1.03 & 0.39 & 2.05 \\
\hline$X 6-4-4$ & 24.0 & 1.81 & 0.40 & 12.2 & 0.788 & 0.41 & $1.97^{\mathrm{a}}$ \\
\hline $\mathrm{X} 10-4$ & 20.9 & 1.52 & 0.42 & 11.0 & 0.750 & 0.37 & 1.90 \\
\hline$X 8-3-5$ & 11.2 & 0.608 & 0.46 & 4.53 & 0.334 & 0.48 & $2.47^{\mathrm{a}}$ \\
\hline$X 8-3-8$ & 7.40 & 0.350 & 0.50 & 3.48 & 0.278 & 0.51 & $2.13^{\mathrm{a}}$ \\
\hline
\end{tabular}

a Taken from ref 1 .

* Henley's cadoxen differs from ours in regard to the content of sodium hydroxide (NaOH); it contained about $0.5 \mathrm{~N} \mathrm{NaOH}$, but ours none. 


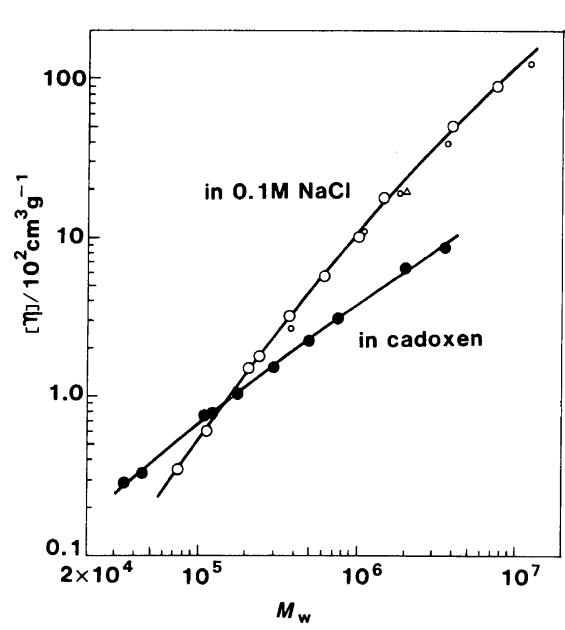

Figure 1. Double-logarithmic plots of $[\eta]$ vs. $M_{w}$ for $\mathrm{Na}$ salt xanthan in $0.1 \mathrm{M}$ aqueous $\mathrm{NaCl}$ and cadoxen at $25^{\circ} \mathrm{C}$. Triangle and smaller unfilled circles, data of Rinaudo and $\mathrm{Milas}^{11}$ in $0.1 \mathrm{M}$ aqueous $\mathrm{NaCl}$ and those of Holzwarth ${ }^{12}$ in $0.75 \mathrm{M}$ aqueous $\mathrm{NaCl}-0.04 \mathrm{M}$ phosphate, respectively.

along with those of $M_{w}$ (in $0.1 \mathrm{M} \mathrm{NaCl}$ ) $/ M_{w}$ (in cadoxen). The ratios $M_{w}$ (in $0.1 \mathrm{M} \mathrm{NaCl}$ )/ $M_{w}$ (in cadoxen) for the newly added four samples X5-6, X9-3, X6-3-7, and X10-4 are about 2 , giving further support to the previous conclusion $^{1}$ that the predominant species of $\mathrm{Na}$ salt xanthan in $0.1 \mathrm{M}$ aqueous $\mathrm{NaCl}$ is a dimer.

Double-logarithmic plots of $[\eta]$ in $0.1 \mathrm{M}$ aqueous $\mathrm{NaCl}$ and cadoxen against $M_{w}$ are shown in Figure 1. The two curves in the figure have distinctly different slopes and intersect at an $M_{w}$ of about $2 \times 10^{5}$. This feature is very similar to that found previously ${ }^{1}$ for the molecular weight dependence of $\left\langle S^{2}\right\rangle^{1 / 2}$. The slope for $0.1 \mathrm{M} \mathrm{NaCl}$ is about 1.5 below $M_{w} \sim 2.5 \times 10^{5}$ and about unity above $M_{w} \sim$ $10^{6}$. The former indicates a high stiffness of the xanthan dimer. The slope for cadoxen is about 0.87 below and about 0.70 above $M_{w} \sim 1.5 \times 10^{5}$. The latter is compatible with the previous conclusion ${ }^{1}$ from $\left\langle S^{2}\right\rangle$ that the single molecule of $\mathrm{Na}$ salt xanthan in cadoxen is flexible, but the former suggests that this molecule should not be completely flexible but somewhat stiff, as has been shown for similar $\beta$-1,4-D-glucans. ${ }^{9,10}$

The triangle and smaller unfilled circles in Figure 1 represent, respectively, the data of Rinaudo and $\mathrm{Milas}^{11}$ in $0.1 \mathrm{M}$ aqueous $\mathrm{NaCl}$ and those of Holzwarth ${ }^{12}$ in $0.75 \mathrm{M}$ aqueous $\mathrm{NaCl}-0.04 \mathrm{M}$ phosphate, $\mathrm{pH}$ 7. Their agreement with our data points is quite good. However, note that Holzwarth's molecular weights were estimated indirectly from $[\eta]$ and $s_{0}$ (the sedimentation coefficient), assuming the $\beta$ parameter in the Flory-ScheragaMandelkern equation ${ }^{13}$ to be $2.5 \times 10^{6}$ (in conventional units).

\section{Double-Stranded Helix}

The viscosity curve for $0.1 \mathrm{M}$ aqueous $\mathrm{NaCl}$ in Figure 1 indicates that the xanthan dimer may be modeled as a semiflexible rod. According to Yamakawa-Yoshizaki's theory ${ }^{14}$ (a modification of Yamakawa-Fujii's theory $\left.^{9}\right),[\eta]$ of the Kratky-Porod wormlike chain, a typical model chain for semiflexible rods, is described by three parameters, $M_{\mathrm{L}}$ (the molar mass per unit contour length of the chain), $q$ (the persistence length), and $d$ (the chain diameter). With $M_{\mathrm{L}}$ and $q$ fixed to $1940 \mathrm{~nm}^{-1}$ and $120 \mathrm{~nm}$ determined previously ${ }^{1}$ from $\left\langle S^{2}\right\rangle$ data for $\mathrm{Na}$ salt xanthan in $0.1 \mathrm{M}$ aqueous $\mathrm{NaCl}$, we searched for a $d$ value leading to the best fit of our $[\eta]$ data in $0.1 \mathrm{M}$ aqueous $\mathrm{NaCl}$ to Yamakawa-Yoshizaki's theory.

A comparison of theory and experiment is illustrated in Figure 2, in which the theoretical curve has been computed with a $d$ value of $2.2 \mathrm{~nm}$. A close fit of this curve to the unfilled circles indicates that the $[\eta]$ data are fully consistent with the previous $\left\langle S^{2}\right\rangle$ data. The molar mass per main chain glucose residue for our xanthan samples is $460 \mathrm{~g} \mathrm{~mol}^{-1}{ }^{1}$ which is combined with $M_{\mathrm{L}}$ of $1940 \mathrm{~nm}^{-1}$ to yield $0.47 \mathrm{~nm}$ for the contour length per main chain residue of the xanthan dimer. This contour length equals the pitch $(0.47 \mathrm{~nm})$ per residue of the $5_{1}$ double-stranded helix ${ }^{2}$ proposed for 


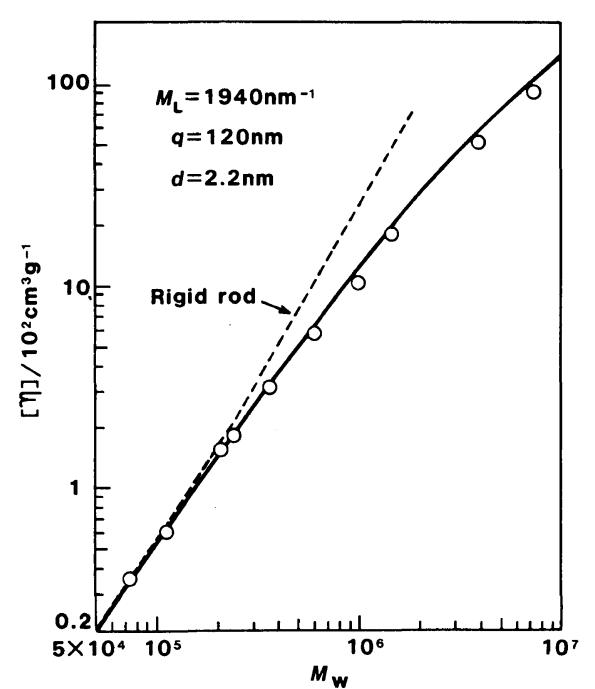

Figure 2. Comparison between the measured $[\eta]$ for $\mathrm{Na}$ salt xanthan in $0.1 \mathrm{M}$ aqueous $\mathrm{NaCl}$ and the theoretical values calculated from Yamakawa-Yoshizaki's theory ${ }^{16}$ for wormlike chains with the indicated parameter values.

the crystalline structure of xanthan, thus confirming the previous finding ${ }^{1}$ that the xanthan dimer in $0.1 \mathrm{M}$ aqueous $\mathrm{NaCl}$ has the 5 double-stranded helical structure.

For $M_{\mathrm{L}}=1940 \mathrm{~nm}^{-1}$ and $q=120 \mathrm{~nm}$, Yamakawa-Yoshizaki's theory could be fitted to our $[\eta]$ data as closely as the curve in Figure 2 with any values of $d$ ranging from 2 to 2.5 $\mathrm{nm}$. Such $d$ values are comparable with 1.9 $2.2 \mathrm{~nm}$ estimated from Okuyama et al.'s crystallographic data ${ }^{2}$ and their molecular model ${ }^{2}$ for the $5_{1}$ double-stranded helix of xanthan, but are only about one half the value $(4 \mathrm{~nm})$ estimated by Holzwarth and Prestridge ${ }^{15}$ from electron micrographs.

The dashed line in Figure 2 represents the theoretical values calculated with $M_{\mathrm{L}}=$ $1940 \mathrm{~nm}^{-1}$ and $d=2.2 \mathrm{~nm}$ from YoshizakiYamakawa's theory ${ }^{16}$ for rigid rods. Its fit to the data points is limited only to $M_{w}$ below $2.5 \times 10^{5}$. Rinaudo and Milas ${ }^{11}$ found that their data of $\left\langle S^{2}\right\rangle$, $[\eta]$ (the triangle in Figure 1), and $s_{0}$ for an $\mathrm{Na}$ salt xanthan sample with $M_{w}=2 \times 10^{6}$ in $0.1 \mathrm{M}$ aqueous $\mathrm{NaCl}$ are com-

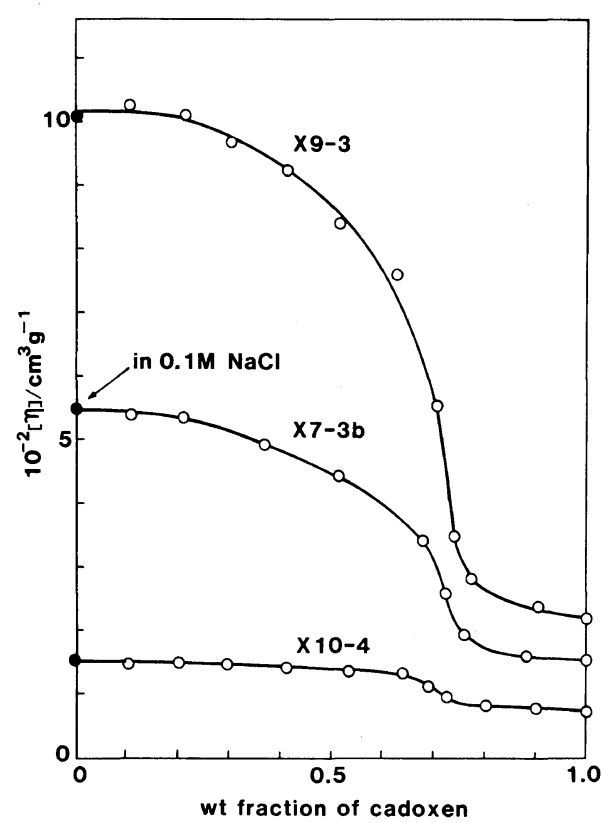

Figure 3. Composition dependence of $[\eta]$ for samples X9-3, X7-3b, and X10-4 in cadoxen-water mixtures at $25^{\circ} \mathrm{C}$.

patible with a single rigid-rod molecule. However, it is evident from Figure 2 that their xanthan in $0.1 \mathrm{M}$ aqueous $\mathrm{NaCl}$ could not be completely rigid.

\section{Dissociation of the Double Helix}

Figure 3 depicts the composition dependence of $[\eta]$ for samples X9-3, X7-3b, and X104 in water-cadoxen mixtures at $25^{\circ} \mathrm{C}$. For $w$ (the weight fraction of cadoxen in the mixture) below $0.2,[\eta]$ is essentially independent of $w$, indicating that the double helix of $\mathrm{Na}$ salt xanthan in $0.1 \mathrm{M}$ aqueous $\mathrm{NaCl}$ remains intact in this composition range. With increasing $w$ above $0.2,[\eta]$ decreases first gradually and then steeply, and finally converges to the value in pure cadoxen. This change in $[\eta]$ represents the dissociation of the xanthan double helix into two single chains induced by addition of cadoxen to an aqueous xanthan. It should be noted that the substantial change in $[\eta]$ occurs in a narrow range of $w$ from 0.6 to 0.7 , regardless of the length of the double helix. 


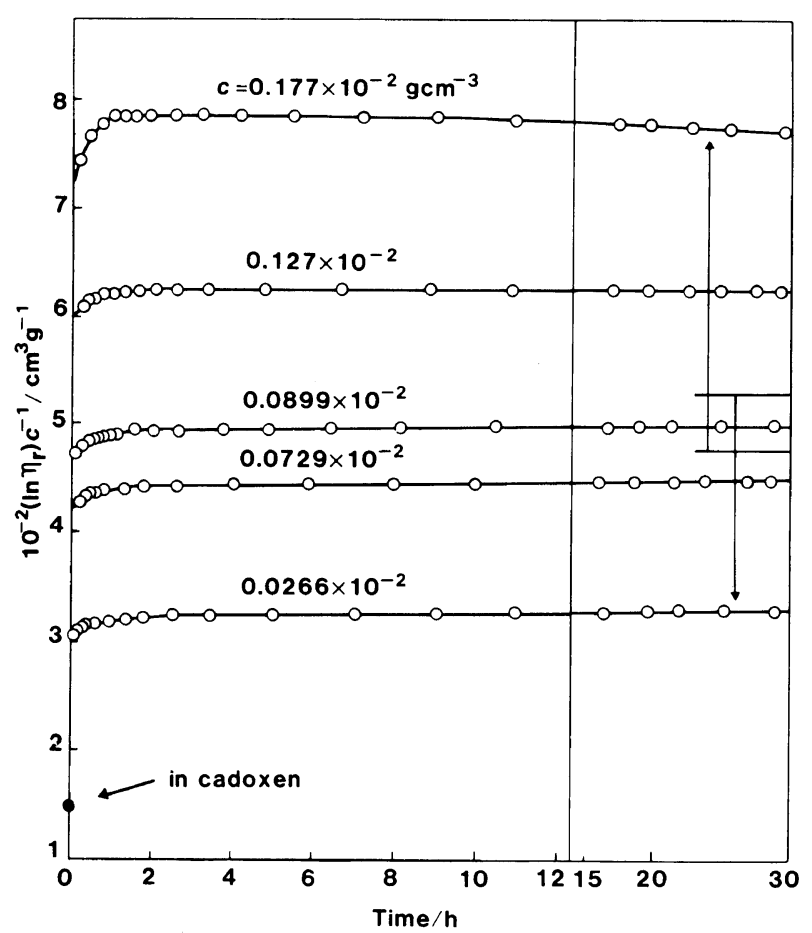

Figure 4. Changes in viscosity at $25^{\circ} \mathrm{C}$ with time following dilution of cadoxen solutions of sample $\mathrm{X} 7-3 \mathrm{~b}$ with water to $10 \mathrm{wt} \%$ cadoxen. See the text as for the horizontal segments.

The $k^{\prime}$ values in water-cadoxen mixtures were normal, ranging from 0.34 to 0.43 . This implies that the degree of dissociation of the xanthan double helix into single chains is not affected by the polymer concentration.

\section{Association of Single Chains in Water-Diluted Cadoxen}

Figure 4 shows time changes in $\left(\ln \eta_{\mathrm{r}}\right) / c$ that occurred after cadoxen solutions of sample X7-3b were diluted with water to $w=0.10$. Here, $\eta_{\mathrm{r}}$ and $c$ denote the relative viscosity and the polymer mass concentration, respectively, and the horizontal segments represent the values of $\left(\ln \eta_{\mathrm{r}}\right) / c$ obtained when the same sample was directly dissolved in a water-cadoxen mixture of $w=0.10$ at the indicated $c$. The initial steep rise of each curve is followed by a rapid leveling off [the $\left(\ln \eta_{\mathrm{r}}\right) / c$ values at zero time, i.e., those in pure cadoxen, are (1.471.52) $\left.\times 10^{2} \mathrm{~cm}^{3} \mathrm{~g}^{-1}\right]$, and the plateau height depends strongly on $c$. It should be noted that the plateau for the lowest $c$ appears far below the segment for this concentration, and that for the highest $c$ far above the corresponding segment. This $c$ dependence of the plateau value indicates that addition of water causes single xanthan chains in cadoxen to aggregate intermolecularly.

After the curves for $c=0.177 \times 10^{-2}$ and $0.0899 \times 10^{-2} \mathrm{~g} \mathrm{~cm}^{-3}$ in Figure 4 were determined, the solutions of these concentrations were further diluted with a cadoxen-water mixture of $w=0.10$ to different $c$. The changes in $\left(\ln \eta_{\mathrm{r}}\right) / c$ accompanying the dilution were normal, yielding $[\eta]=7.71 \times 10^{2}$ and $5.19 \times 10^{2} \mathrm{~cm}^{3} \mathrm{~g}^{-1}$ for the solutions whose original $c$ were $0.177 \times 10^{-2}$ and $0.0899 \times 10^{-2}$ $\mathrm{g} \mathrm{cm}^{-3}$, respectively. The former $[\eta]$ is larger than that for the same sample X7-3b dissolved directly in a cadoxen-water mixture of $w=0.10$ (Figure 3), indicating that dilution 


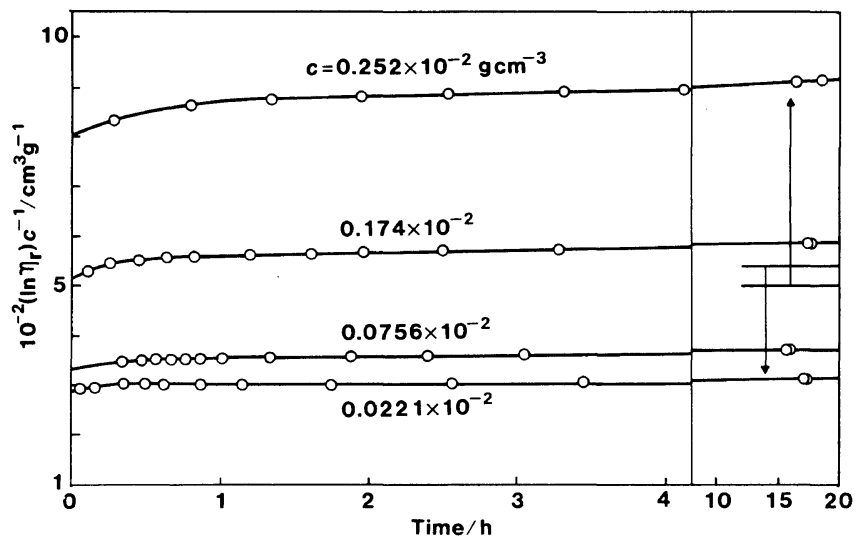

Figure 5. Changes in viscosity at $25^{\circ} \mathrm{C}$ with time after $\mathrm{NaCl}$ was added to preheated (at $95^{\circ} \mathrm{C}$ for $15 \mathrm{~min}$ ) aqueous solutions of sample $\mathrm{X} 7-3 \mathrm{~b}$ to $0.1 \mathrm{M}$. See the text as for the horizontal segments.

with the mixed solvent could not dissociate the aggregates that had been present in the solution before dilution.

In conclusion, we found that once dissociated completely into single chains in cadoxen, the double-helical dimer of $\mathrm{Na}$ salt xanthan was no longer restored by addition of water to the solution or by further dilution with a cadoxen-water mixed solvent.

\section{Salt-Induced Association of Single Chains}

It is widely accepted that xanthan in pure water can be dispersed molecularly at elevated temperature. ${ }^{3-5,15,17}$ We asked ourselves whether the single chains in such a solution restore a double-helical dimer when the solvent is changed to $0.1 \mathrm{M}$ aqueous $\mathrm{NaCl}$ at $25^{\circ} \mathrm{C}$. Thus, pure water solutions of sample $\mathrm{X} 7-3 \mathrm{~b}$ were heated at $95^{\circ} \mathrm{C}$ for $15 \mathrm{~min}$, cooled to $25^{\circ} \mathrm{C}$, and mixed with aqueous $\mathrm{NaCl}$ to an $\mathrm{NaCl}$ concentration of $0.1 \mathrm{M}$.

The viscosities of the salt solutions are shown in Figure 5. Here, the horizontal segments represent the values of $\left(\ln \eta_{\mathrm{r}}\right) / c$ (not corrected for shear-rate effect) at the indicated $c$ for sample X7-3b dissolved directly in $0.1 \mathrm{M}$ aqueous $\mathrm{NaCl}$ at $25^{\circ} \mathrm{C}$. The $c$ dependence of plateau values and their relation to the horizontal segments are very similar to those for the water-diluted cadoxen solutions of $w=0.10$ in
Figure 4. This indicates that addition of $\mathrm{NaCl}$ does not cause single xanthan chains in pure water at $95^{\circ} \mathrm{C}$ to reform a double-helical dimer but associate them to aggregates, and supports the conclusion of Holzwarth and Prestridge ${ }^{15}$ from electron microscopic observations. However, they argued the aggregates to be double helices consisting of more than two chains. Nothing can be inferred about the structure of such aggregates from the present viscosity data alone.

\section{Comments on Spectroscopic Studies}

Several groups of authors ${ }^{3-5,18,19}$ claimed that the conformation of xanthan in aqueous salt solution is a single-stranded helix, instead of a double-stranded helix, on the basis of the following polarimetric observations:

(1) Xanthan in aqueous solution of low ionic strength underwent an order-disorder change in conformation with a change in salt concentration or temperature, but the observed changes in optical rotation $[\alpha]$ did not depend on $c$ (Morris et $a l^{3}$ and Milas and Rinaudo ${ }^{4}$.

(2) Salt-induced disorder-order changes followed a first order kinetics when monitored by stopped flow polarimetry in the time scale shorter than $10 \mathrm{~s}$ (Norton et al. ${ }^{5}$ ).

The concentration independent changes in 
$[\alpha]$, mentioned in (1), do not always prove the conformation changes to have occurred in a single chain, because, as shown above, the dissociation of the xanthan dimer into single chains occurs with no measurable $c$ dependence.

On the other hand, the finding (2) appears to show conclusively that disordered chains became intramolecularly ordered by the addition of a salt. It conflicts our finding that the single chains of xanthan in cadoxen at $25^{\circ} \mathrm{C}$ or in pure water at $95^{\circ} \mathrm{C}$ associated intermolecularly when the solvent was made favorable to the formation of a double helix by addition of water or $\mathrm{NaCl}$. However, Norton et al.'s stopped flow polarimetry ${ }^{5}$ was concerned with a time scale much shorter than that of our viscosity measurement. Therefore, their experiment observed only a very early stage of the salt-induced conformation change in xanthan, and had nothing to do with what we found from viscosity measurements: interchain association.

It was shown ${ }^{20}$ that when denatured collagen was allowed to renature by lowering the temperature, the process followed a first order kinetics at its early stage. Since the unimolecular reaction was apparently incompatible with the reformation of the triple helical structure of native collagen, this finding was explained as due to the transitory formation of an intermediate consisting of a single helical chain. ${ }^{20,21}$ On the other hand, the renaturation of collagen at its later stage was shown by light scattering and viscometry ${ }^{20,22}$ to involve the formation of aggregates, a multimolecular reaction. These kinetic features of collagen renaturation resemble what was observed at the early and later stages of salt-induced conformation changes in xanthan.

\section{REFERENCES}

1. T. Sato, T. Norisuye, and H. Fujita, Polym. J., 16, 341 (1984).

2. K. Okuyama, S. Arnott, R. Moorhouse, M. D. Walkinshaw, E. D. T. Atkins, and Ch. Wolf-Ullish, in "Fiber Diffraction Methods," A. D. French and K. H. Gardner Ed., ACS Symp. Ser. No. 141, Am. Chem. Soc., Washington, D.C., 1980, p 411.

3. E. R. Morris, D. A. Rees, G. Young, M. D. Walkinshaw, and A. Darke, J. Mol. Biol., 110, 1 (1977).

4. M. Milas and M. Rinaudo, Carbohydr. Res., 76, 189 (1979).

5. I. T. Norton, D. M. Goodall, E. R. Morris, and D. A. Rees, J. Chem. Soc., Chem. Commun., 545 (1980).

6. M. L. Huggins, J. Am. Chem. Soc., 64, 2716 (1942).

7. D. J. Mead and R. M. Fuoss, J. Am. Chem. Soc., 64, 277 (1942).

8. D. Henley, Arkiv. Kemi., 18, 327 (1961).

9. H. Yamakawa and M. Fujii, Macromolecules, 7, 128 (1974).

10. S. Dayan, P. Maissa, M. J. Vellutini, and P. Sixou, Polymer, 23, 800 (1982).

11. M. Rinaudo and M. Milas, Biopolymers, 17, 2663 (1978).

12. G. Holzwarth, Carbohydr. Res., 66, 173 (1978).

13. L. Mandelkern and P. J. Flory, J. Chem. Phys., 20, 212 (1952); L. Mandelkern, W. R. Krigbaum, H. A. Scheraga, and P. J. Flory, J. Chem. Phys., 20, 1392 (1952).

14. H. Yamakawa and T. Yoshizaki, Macromolecules, 13, 633 (1980).

15. G. Holzwarth and E. B. Prestridge, Science, 197, 757 (1977).

16. T. Yoshizaki and H. Yamakawa, J. Chem. Phys., 72, 57 (1980).

17. G. Holzwarth, Biochemistry, 15, 4333 (1976).

18. D. A. Rees, Pure Appl. Chem., 53, 1 (1981).

19. S. A. Frangou, E. R. Morris, D. A. Rees, R. K. Richardson, and S. B. Ross-Murphy, J. Polym. Sci., Polym. Lett. Ed., 20, 531 (1982).

20. A. Veis, "The Macromolecular Chemistry of Gelatin," Academic Press, New York and London, 1964, Chapter V.

21. P. J. Flory and E. S. Weaver, J. Am. Chem. Soc., 82, 4518 (1960).

22. J. Engel, Arch. Biochem. Biophys., 97, 150 (1962). 